\title{
Tissue Sampling through Endoscopic Ultrasound-Guided Fine Needle Aspiration versus Endoscopic Retrograde Cholangiopancreatographic Brushing Cytology Technique in Suspicious Malignant Biliary Stricture
}

\author{
Elham Sobhrakhshankhah ${ }^{1}$, Masoudreza Sohrabi ${ }^{1}$, Hamid Reza Norouzi ${ }^{1}$, Farhad Zamani ${ }^{1}$, \\ Hossein Ajdarkosh ${ }^{1}$, Mehdi Nikkhah ${ }^{1}$, Mahmood Reza Khoonsari ${ }^{1}$, Amir Hossein Faraji ${ }^{1, *}$
}

1. Gastrointestinal and Liver Disease Research Center (GILDRC), Iran University of Medical Sciences (IUMS), Tehran, Iran

\footnotetext{
* Corresponding Author:

Amirhossein Faraji, MD Gastrointestinal and Liver Disease Research Center (GILDRC), Firoozgar Hospital,ValiasrSq. Tehran,Iran

Telefax: + 982188941831

Email: ami.hfaraji@yahoo.com

Received: 25 Dec. 2020

Accepted: 09 Jun. 2021
}

\section{ABSTRACT}

\section{BACKGROUND}

Differentiation of benign and malignant biliary strictures plays a pivotal role in managing biliary strictures. Brush cytology via endoscopic retrograde cholangiopancreatography (ERCP) and endoscopic ultrasound-guided fine-needle aspiration (EUS-FNA) are two diagnostic methods. In the present study, we aimed to compare the accuracy of the results of EUS-FNA and ERCP-based sampling of biliary strictures.

\section{METHODS}

In a prospective study, between January 2019 and March 2020, patients with indeterminate biliary strictures who had no history of hepatobiliary surgery, opium usage, cancer of pancratobiliary system, and acute liver disease were selected. They underwent EUS and ERCP in the same session. They were followed up for 6 months, and the sensitivity, specificity, positive and negative predictive values, and accuracy of these imaging modalities were compared.

\section{RESULTS}

A total of 60 patients were enrolled. 28 lesions were located in the distal and 32 lesions in the proximal parts of the biliary tree. 55 malignant and 5 benign lesions were diagnosed. The sensitivity and accuracy of EUS-FNA and ERCP tissue sampling were $78.2 \%$ and $80.0 \%$ versus $50.9 \%$ and $55.0 \%$, respectively ( $p=0.024$ ). The combination of both methods improved the sensitivity and accuracy to $85.5 \%$ and $86.7 \%$, respectively. Regarding the location, EUS-FNA is superior to ERCP-brush cytology in diagnosing proximal lesions with sensitivity and specificity of $73.3 \%$ and $75.0 \%$ vs. $50.0 \%$ and $53.1 \%$, respectively $(p=0.04)$.

\section{CONCLUSION}

EUS-FNA is superior to ERCP brushing in the diagnosis of indeterminate biliary strictures, particularly in distal lesions. Combining ERCP brushing and EUS-FNA improves the diagnosis accuracy.

\section{KEYWORDS:}

Endoscopic ultrasound-guided fine-needle aspiration, ERCP, Cytology, Biliary tract neoplasms, cholangiocarcinoma

\footnotetext{
Please cite this paper as:

Sobhrakhshankhah E, Sohrabi M, Norouzi MR, Zamani F, Ajdarkosh H, Nikkhah M, Khoonsari MR, Faraji A Tissue Sampling through Endoscopic Ultrasound-Guided Fine Needle Aspiration versus Endoscopic Retrograde Cholangiopancreatographic Brushing Cytology Technique in Suspicious Malignant Biliary Stricture. Middle East J Dig Dis 2021;13:294-301. doi: 10.34172/mejdd.2021.238.
} 


\section{INTRODUCTION}

Biliary strictures are challenging clinical issues that make difficulties for curative or palliative therapeutic approaches. Similarities of benign and malignant neoplasia of biliary tree provoke the necessity of implementing tissue sampling and histology assessment, although other data such as clinical and laboratory data may help to distinguish the benign and malignant biliary strictures. ${ }^{1,2}$ In this regard, strictures following inflammation and surgery on the biliary tract can be considered as the most common causes of benign biliary strictures, while the most common malignant aetiologies are cholangiocarcinoma tumors of adjacent organs that invade the biliary tract, and metastatic tumors, or lymph node. ${ }^{3,4}$

Non-invasive modalities for diagnosis of an indeterminate biliary stricture include the following: serum tumor markers, radiological imaging such as magnetic resonance (MR), computed tomography (CT), cholangiography, ultrasound scan (USS), and positron emission tomography (PET). In addition, there are two main interventional modalities launched to diagnose indeterminate biliary strictures, including endoscopic retrograde cholangiopancreatography (ERCP) sampling methods and endoscopic ultrasound (EUS) guided fine needle aspiration (EUS-FNA). ${ }^{4,5}$ Thus, during ERCP and EUS there are possibilities of implementing the imaging and molecular modalities such as cholangioscopy, optical coherence tomography, intraductal ultrasound, confocal endomicroscopy, and EUS-elastography and contrast-enhanced image. Nevertheless, tissue samplings remain the gold standard for diagnostic purposes.

ERCP method is a conventional method that has commonly been used for diagnoses, tissue acquisitions, and eventually therapeutic interventions such as balloon dilatations or stent insertions. ${ }^{6,7}$ The main ERCP-based method for tissue sampling is brush cytology with low sensitivity, about $35 \%$. EUS-FNA was recently introduced as the modality of diagnosis and tissue sampling. The reported data revealed that EUS-FNA has a sensitivity of $50-95 \%$ in diagnosing indeterminate biliary obstructions. Also, its sensitivity and specificity for malignant biliary stricture reached $80 \%$ and $97 \%$, respectively, even in the identifiable masses. ${ }^{1,8,9}$

Despite the widespread use of ERCP as well as EUS in the diagnosis of biliary stricture, there is no sufficient data to compare these modalities. In this study, we conducted prospective research with follow-up to evaluate and compare the performance and diagnosis by ERCP brush cytology and
EUS-FNA in the same-session procedures.

\section{MATERIALS AND METHODS}

\section{Patient selection}

This is a cross-sectional study that was conducted from January 2019 to March 2020. A total number of 75 adult patients with suspected malignant biliary stricture who had the inclusion criteria participated in this study.

According to sample size calculation, we required 54 patients (the number of patients was calculated via formula as $\mathrm{n}=(\mathrm{Z} 1-\alpha / 2) \operatorname{Sn}(1-\mathrm{Sn}) / \mathrm{d} 2$ in which $\alpha=$ $5 \% ; \mathrm{Sn}=90 \%$ and $\mathrm{d}=8 \%$ ).

r15 patients were excluded. The remaining patients were followed up for at least 6 months for progression of the disease or death. Included patients were over 18 years old who were suspected of having malignant biliary strictures based on the clinical manifestations such as painless obstructive jaundice, physical examinations, laboratory data, and imaging studies such as CT or MRI. Exclusion criteria were as follows: patients with a previous diagnosis of chronic pancreatitis or other pancreaticobiliary disorders without malignant concerns, patients with altered anatomy (such as previous gastrojejunostomy), pregnancy, history of allergy to dye, bile duct stricture due to pancreatic cancer, gall bladder cancer, ampullary cancer, and inadequate data and follow-up records.

The malignant strictures were defined as positive cytology, advancing the illness, or death due to cholangiocarcinoma during the follow-up.

\section{Procedures}

\section{Technical description}

After 8 hours of fasting, deep sedation with propofol \& fentanyl was performed. All patients underwent EUSFNA, followed by ERCP-brush biopsy in the prone position during a single session. An echo-endoscope (GF-UC140; Olympus America, Center Valley, Pa) was used for EUS procedures. A 22- or 25-gauge needle (Echotip; Boston Company, USA) was used for FNA and tissue acquisition. Four passes were realized as soon as the localization of strictures was done during EUS-FNA. Two punctures with a $10-\mathrm{mL}$ vacuum pressure syringe 
technique and two punctures with a stylet slow pull technique were performed.

The needle was moved back and forth in the lesion about 20 times in each puncture.

All FNA procedures were performed with the presence of cytopathologic assessment on site. The specimen was expressed onto 1 to 2 slides for rapid evaluation by air-dried and/or alcohol-fixed review. The DiffQuik stain was used in the preparation of air-dried smears; toluidine blue followed by Papanicolaou staining was used to prepare the alcohol-fixed smears. Additional material was placed in a $30-\mathrm{mL} 10 \%$ formalin container for subsequent cell-block analysis.

According to the policy of our canter, all patients received $100 \mathrm{mg}$ indomethacin rectally to prevent postERCP pancreatitis immediately before the procedure.

We used the following devices in sequential order: a conventional, over-the-guidewire cytology brush (Fusion Cytology Brush; Cook Medical) to perform the sampling by ERCP (TJF-240; Olympus, Tokyo, Japan side view duodenoscope). No dilation was executed before tissue sampling. Cytology brushings were obtained using 10 to-and-fro brushing strokes across the biliary stricture.

ERCP-brushing cytology was performed until at least three representative tissue fragments were obtained.

The brush was then smeared on two glass slides that were air-dried and placed in a 95\% ethyl alcohol fixative container. The tip of the brush was cut and submitted in a $10 \%$ formalin container for analysis.

The EUS and ERCP procedures were performed by two separate endoscopists.

\section{Histological evaluation}

Two pathologists were involved in the biliopancreatic pathway, and based on the World Health Organization (WHO) classification criteria, ${ }^{10}$ performed the analysis. The anatomopathological results of the specimens were classified into four categories; negative, suspected for malignancy, positive, and inconclusive.

If no sign of malignant, suspicious, or atypical cells was seen, the results were considered negative. The samples were considered suspected for malignancy when they contained suspicious or atypical cells and positive when the samples contained malignant cells. When the cell sample was insufficient for analysis, the results were considered inconclusive. Then for differentiating the neoplastic from the non-neoplastic lesions, immunohistochemical stains were used when needed.

\section{Statistical analysis:}

The quantitative variables, including minimum and maximum, mean, median, and standard deviation, were analyzed. The qualitative variables, including absolute and relative frequencies, were calculated.

First, we analyzed the overall sensitivity and accuracy of EUS-FNA and ERCP tissue sampling in patients who were suspected of having malignant biliary obstruction. Then comparative analyses of EUS-FNA and ERCP-based tissue sampling for subsets of patients with bile duct masses/strictures and indeterminate strictures (defined as obstructive jaundice without visible mass on preprocedure CT or MRI) were performed. We used Fisher exact test to check statistically significant differences between EUS-FNA and ERCP sampling.

The intention-to-treat (ITT) analysis (failure of the methods was considered benign results) was performed. Cases with a suspected diagnosis of malignancy were considered both benign and malignant. We used CATMAKER software to evaluate the accuracy, sensitivity, specificity, positive predictive values, and negative predictive values. All tests were evaluated using SPSS software version 23.0, using a significance level of $5 \%$.

\section{Ethics}

Principles of the Declaration of Helsinki were considered. The study was approved by the Ethics Committee of Iran University of Medical Sciences; ethics code: IR.IUMS. FMD.REC.1399.019. The research protocol was explained to patients by a physician, and written informed consent was signed by each of them before the study.

\section{RESULTS}

A total of 60 patients (21 women and 39 men), with a mean age of $63.12 \pm 11.64$ years) were recruited in the study (figure 1).

\section{Characteristics of the study participants}

The basic characteristics of study participants were summarized in table1.

Based on ERCP assessment, malignancy was reported 


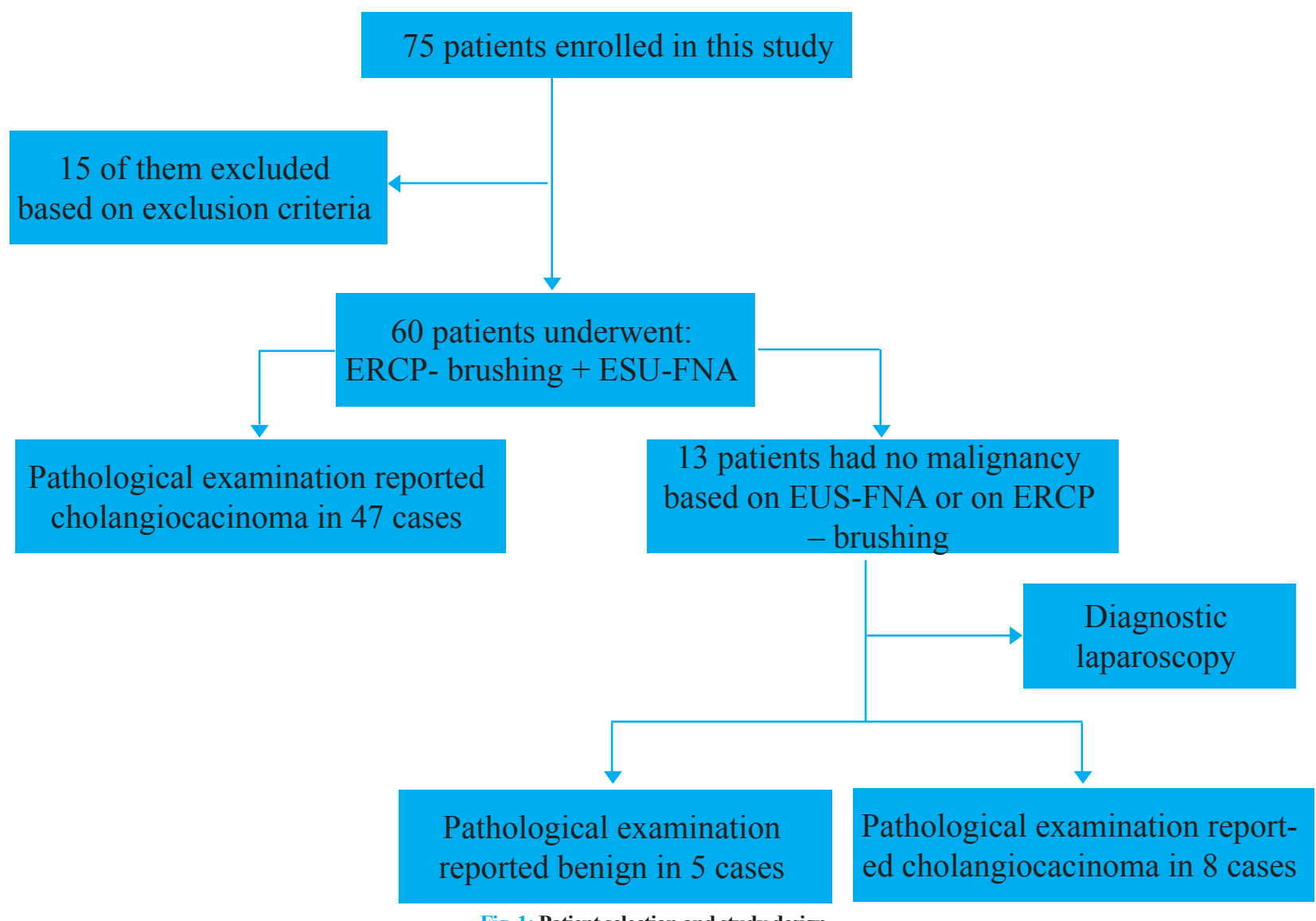

Fig. 1: Patient selection and study design

in 28 patients, and 32 patients' pathological findings indicated that the lesion was benign or no results of malignancy were noticed. Regarding EUS-FNA findings, 43 patients had a malignant stricture. All of them had cholangiocarcinoma. Other pathologies were not detected. Also, in the remaining 17 patients, the pathology did not show malignant cells. Table 2 illustrates the prevalence of stricture according to location and the modalities.

Comparing the sensitivity and accuracy of diagnostic methods, we observed that EUS was superior to ERCP in tissue sampling $(78.2 \%$ and $80.0 \%$ versus $50.9 \%$ and $55.0 \%)(p=0.024)$.

The diagnostic accuracy rate, sensitivity rate, specificity rate, positive predictive value, and negative predictive value for diagnostic methods used are shown separately in table 3.

Our findings point to the strength of diagnostic indicators increased so that the sensitivity rate reached $85.5 \%$, the specificity rate reached $100 \%$, and the diagnostic accuracy rate reached $86.7 \%$.

Also, analysis of the accuracy rate of the methods according to the anatomical location of strictures was performed as distal or proximal involvement (table 4). Comparing the sensitivity and accuracy, we observed that EUS was superior to ERCP in tissue sampling in distal stenosis (84.0\% and $85.7 \%$ versus $52.0 \%$ and $57.1 \%$ ), respectively. But this difference was not statistically significant ( $p=0.274)$.

Besides, comparing sensitivity and accuracy rates of diagnostic methods, EUS was found significantly superior to ERCP in tissue sampling in proximal stenosis $(73.3 \%$ and $75.0 \%$ versus $50.0 \%$ and $53.1 \%$ ), respectively ( $p=0.040$ ).

\section{DISCUSSION}

Discriminating benign and malignant biliary stenosis is not an easy matter. ${ }^{1,11}$ In this study, we compared two popular tissue sampling techniques based on EUS-FNA with ERCP-brushing in patients with an indeterminate biliary stricture. Findings revealed that the results of EUS-FNA had significantly higher sensitivity and accuracy than ERCP brushing in the diagnosis of malignant 
Table 1: Demographic and clinical characteristics and final diagnoses of the patients

\begin{tabular}{|c|c|c|}
\hline Variables & & Sum \\
\hline Age, year (mean) & & 63.12 \\
\hline \multirow{2}{*}{ Sex } & Male, No (\%) & $39(65.0)$ \\
\hline & Female, No (\%) & $21(35.0)$ \\
\hline \multirow{4}{*}{ Clinical indication(s) for EUS } & Cholestatic liver tests, No (\%) & $56(93.3)$ \\
\hline & pancreatic mass in imaging, No (\%) & $7(11.7)$ \\
\hline & Bile duct mass in imaging, No (\%) & $24(40.0)$ \\
\hline & Indeterminate stricture*, No (\%) & $29(48.3)$ \\
\hline Technical success for EUS-FNA, No (\%) & & $60(100)$ \\
\hline Technical success for ERCP sampling, No. (\%) & & $60(100)$ \\
\hline Cigarette smoking, no. (\%) & & $16(26.7)$ \\
\hline Drug abuse (opium or industrial), No. (\%) & & $7(11.7)$ \\
\hline \multirow{6}{*}{ Medical History } & Cholecystectomy, No. (\%) & $5(8.3)$ \\
\hline & Pancreatitis, No. (\%) & $7(11.7)$ \\
\hline & Viral hepatitis, no. (\%) & $8(13.3)$ \\
\hline & UC/PSC, No. (\%) & $11(18.3)$ \\
\hline & DM, No. $(\%)$ & $12(20.0)$ \\
\hline & HTN, No. $(\%)$ & $14(23.3)$ \\
\hline \multirow{7}{*}{ Clinical manifestations } & Abdominal pain, No. (\%) & $39(65.0)$ \\
\hline & Weight loss, No. (\%) & $30(50.0)$ \\
\hline & Jaundice, No. (\%) & $53(88.3)$ \\
\hline & Fever, No. (\%) & $7(11.7)$ \\
\hline & Nausea/vomiting, No. (\%) & $17(28.3)$ \\
\hline & Pruritus, No. (\%) & $42(70.0)$ \\
\hline & Bowel habit change, No. (\%) & $10(16.7)$ \\
\hline \multirow{2}{*}{ Final diagnosis } & Malignant (cholangiocarcinoma), No. (\%) & $55(91.7)$ \\
\hline & Benign, No. $(\%)$ & $5(8.3)$ \\
\hline
\end{tabular}

MRI, magnetic resonance imaging. ERCP: Endoscopic retrograde cholangiography;EUS:Endoscopic Ulrasond, EUS-FNA: Endoscopic ultrasound fine-needle aspiration

*Indeterminate stricture defined as jaundice and evidence of biliary obstruction without visible mass on pre-procedure contrast CT or MRI.

Table 2: Anatomical location and final pathological assessment results of strictures according to ERCP brushing and EUS-FNA

\begin{tabular}{ccccccccc}
\hline & \multicolumn{2}{c}{ Location } & \multicolumn{2}{c}{ ERCP } & \multicolumn{2}{c}{ EUS-FNA } & \multicolumn{2}{c}{ ERCP+EUS } \\
\cline { 2 - 9 } & Proximal & Distal & Malignant & Non-malignant & Malignant & Non-malignant & Malignant & Non-malignant \\
\hline $\mathrm{n}$ & 32 & 28 & 28 & 32 & 43 & 17 & 47 & 13 \\
\hline$\%$ & $53.3 \%$ & $46.7 \%$ & $46.7 \%$ & $53.3 \%$ & $71.7 \%$ & $28.3 \%$ & $78.3 \%$ & $21.7 \%$ \\
\hline
\end{tabular}

ERCP: Endoscopic retrograde cholangiography; EUS-FNA: Endoscopic ultrasound fine-needle aspiration

biliary strictures. Also, the accuracy of EUS-FNA in distal biliary lesions was significantly higher. Furthermore, EUS/ERCP combination had higher diagnostic values compared with EUS-FNA.

As a rule, patients with indeterminate biliary strictures underwent ERCP. ${ }^{12}$ In this manner, brushing cytology for the bile duct is almost a simple and safe procedure. In positive cases, it has high specificity and reliability.
Also, the negative result needs to be confirmed with other modalities such as FNA. ${ }^{13,14}$ Furthermore, EUS approach has given better information for the description of the lesions besides obtaining tissue samples via EUS-FNA. In malignant cases, this data may be an important clue for the next therapeutic approach. Regarding the location of lesions, our results were compared with previous reports. EUS-FNA has higher performance in diagnosing 
Table 3: Diagnostic indices in the intention-to-treat analysis

\begin{tabular}{lccc}
\hline & $\begin{array}{c}\text { ERCP- } \\
\text { Brushing }\end{array}$ & $\begin{array}{c}\text { EUS- } \\
\text { FNA }\end{array}$ & Both Modalities \\
\hline Sensitivity & $50.9 \%$ & $78.2 \%$ & $85.5 \%$ \\
\hline Specificity & $100 \%$ & $100 \%$ & $100 \%$ \\
\hline $\begin{array}{l}\text { Positive predictive } \\
\text { value }\end{array}$ & $100 \%$ & $100 \%$ & $100 \%$ \\
\hline $\begin{array}{l}\text { Negative predic- } \\
\text { tive value }\end{array}$ & $15.6 \%$ & $29.4 \%$ & $38.5 \%$ \\
\hline Accuracy & $55.0 \%$ & $80.0 \%$ & $86.7 \%$ \\
\hline
\end{tabular}

ERCP: Endoscopic retrograde cholangiography; EUS: Endoscopic ultrasonography

bile duct stenosis in both distal and proximal portions. ${ }^{11}$, 12, 15, 16 Sensitivity for the diagnosis of proximal lesions was lower compared with the distal type (59\% vs. $81 \%$ ) ( $p$ $=0.039) \cdot{ }^{12,17,18}$ In fact, lesions located in proximal stenosis, in addition to the greater distance from the duodenal wall, tend to grow and infiltrate the bile duct rather than to form solid masses. ${ }^{19}$ Other studies have reported high sensitivities (77-89\%) for the diagnosis of proximal tumors (hilar tumors) with EUS. ${ }^{1,20}$ In our study, both distal and proximal malignancy illustrated high sensitivity rates (84.0\% and $73.3 \%$, respectively), although we found that EUS-FNA can detect distal cholangiocarcinoma better than proximal cholangiocarcinoma. Also, the diagnostic accuracy rate in distal lesions was $85.7 \%$ and in proximal lesions was $75.0 \%$. The sensitivity of EUS-FNA in heterogeneous bile duct stenosis ranged from $46 \%$ to $100 \%$ in various studies $20-22$ and specifically for intraductal lesions between $53 \%$ to $89 \%{ }^{23,24}$ Oppong and colleagues, in a retrospective study, compared EUSFNA and cytology brush samples through ERCP in 37 patients with suspected malignant bile duct obstruction. They concluded that EUS-FNA was more sensitive than ERCP brushing (53\% versus 29\%). ${ }^{25}$ Also, Rösch and others, in a prospective comparative study on 50 patients with bile duct stenosis or pancreatic mass, showed that EUS-FNA and ERCP samplings had similar sensitivities (43\% and 54\%, respectively). The low sensitivity for EUS-FNA in this study may have been due to the presence of 22 patients (44\%) who had imaging evidence in favor of benign lesions. Despite the higher sensitivity of EUS among patients with pancreatic tumors, ERCP had more reliable results in patients with biliary tumors. ${ }^{24}$ In general, EUS-FNA is a powerful diagnostic tool, and with its widespread use, we will depend less on ERCP for tissue sampling, ${ }^{14,16}$ as we demonstrated high sensitivity for the EUS-FNA method (78.2\%).

In the present study, we also checked out the accuracy of EUS-FNA and ERCP together. We implemented the two methods in the same sedation. The sensitivity, specificity, and accuracy of this diagnostic approach reached $85.5 \%, 100 \%$, and $86.7 \%$, respectively. They are similar to other reports. According to previous studies, performing EUS-FNA with ERCP in one day can increase the diagnostic rate in a short time. ${ }^{20,23,24}$ However, few studies performed ERCP brushing and EUS-FNA in a single session. ${ }^{5,24,25}$ Weilert and colleagues, in a study on 51 patients, reported that EUS-FNA was superior to ERCP in the detection of biliary strictures with sensitivity, specificity, and diagnostic accuracy of 94\%, 100\%, and $90 \%$ versus $50 \%, 50 \%$ and, $53 \%$, respectively. ${ }^{25}$ Although Rösch and co-workers reported no differences between ERCP and EUS-FNA, by combining these two methods, they showed higher diagnostic accuracy. ${ }^{24}$ Altogether, in the presence of suspected malignant biliary strictures, we recommend that both diagnostic procedures be performed concomitantly. The combination of both diagnostic procedures is associated with an increasing number of complications. Our study demonstrated similar complication rates in comparison with studies in which only one diagnostic method was used. ${ }^{24-26}$

In addition, we showed that tissue sampling with EUSFNA and ERCP-brushing had a high positive predictive value in the anatomopathological diagnosis of malignant biliary strictures. The negative predictive value of EUSFNA was higher than ERCP. Ohshima and colleagues ${ }^{27}$ and Fritscher-Ravens and co-workers, ${ }^{23}$ reported negative predictive values of $100 \%$ and $90 \%$, respectively.

In our study, EUS-FNA was superior to ERCP-brushing in the diagnosis of suspected malignant biliary strictures, especially in distal lesions.

Another concern about EUS-FNA sampling is the risk of the tumor spreading into the peritoneum. ${ }^{28}$ However, there is no consensus in this regard. ${ }^{29}$ Higher yields in ERCP sampling can be achieved by performing intraductal cholangioscopy, ${ }^{30,31}$ but due to the poor availability of cholangioscopy, we did not perform it. It is usually considered as a second diagnostic line. 
Table 4: Intention-to-treat analysis, comparing distal and proximal strictures

\begin{tabular}{|c|c|c|c|c|c|c|c|c|c|c|c|c|}
\hline & \multicolumn{6}{|c|}{ Distal } & \multicolumn{6}{|c|}{ Proximal } \\
\hline & \multicolumn{2}{|c|}{ ERCP } & \multicolumn{2}{|c|}{ EUS } & \multicolumn{2}{|c|}{ ERCP + EUS } & \multicolumn{2}{|c|}{ ERCP } & \multicolumn{2}{|c|}{ EUS } & \multicolumn{2}{|c|}{ ERCP + EUS } \\
\hline & Positive & Negative & Positive & Negative & Positive & Negative & Positive & Negative & Positive & Negative & Positive & Negative \\
\hline $\mathrm{N}$ & 13 & 15 & 21 & 7 & 23 & 5 & 15 & 17 & 22 & 10 & 24 & 8 \\
\hline Sensitivity & \multicolumn{2}{|c|}{$52.0 \%$} & \multicolumn{2}{|c|}{$84.0 \%$} & \multicolumn{2}{|c|}{$92.0 \%$} & \multicolumn{2}{|c|}{$50.0 \%$} & \multicolumn{2}{|c|}{$73.3 \%$} & \multicolumn{2}{|c|}{$80.0 \%$} \\
\hline Specificity & \multicolumn{2}{|c|}{$100 \%$} & \multicolumn{2}{|c|}{$100 \%$} & \multicolumn{2}{|c|}{$100 \%$} & \multicolumn{2}{|c|}{$100 \%$} & \multicolumn{2}{|c|}{$100 \%$} & \multicolumn{2}{|c|}{$100 \%$} \\
\hline $\begin{array}{l}\text { Positive } \\
\text { predictive } \\
\text { value }\end{array}$ & \multicolumn{2}{|c|}{$100 \%$} & \multicolumn{2}{|c|}{$100 \%$} & \multicolumn{2}{|c|}{$100 \%$} & \multicolumn{2}{|c|}{$100 \%$} & \multicolumn{2}{|c|}{$100 \%$} & \multicolumn{2}{|c|}{$100 \%$} \\
\hline $\begin{array}{l}\text { Negative } \\
\text { predictive } \\
\text { value }\end{array}$ & \multicolumn{2}{|c|}{$20.0 \%$} & \multicolumn{2}{|c|}{$42.9 \%$} & \multicolumn{2}{|c|}{$60.0 \%$} & \multicolumn{2}{|c|}{$11.8 \%$} & \multicolumn{2}{|c|}{$20.0 \%$} & \multicolumn{2}{|c|}{$25.0 \%$} \\
\hline Accuracy & \multicolumn{2}{|c|}{$57.1 \%$} & \multicolumn{2}{|c|}{$85.7 \%$} & \multicolumn{2}{|c|}{$92.9 \%$} & \multicolumn{2}{|c|}{$53.1 \%$} & \multicolumn{2}{|c|}{$75.0 \%$} & \multicolumn{2}{|c|}{$81.3 \%$} \\
\hline
\end{tabular}

ERCP: Endoscopic retrograde cholangiography; EUS: Endoscopic ultrasonography; Positive: Malignant; Negative: Non-malignant

Regarding complications following procedures, we had no adverse events related to EUS-FNA, but we observed minor adverse events related to ERCP for four cases.

There have been some limitations in the present study. First, we did not perform open or laparoscopic surgery for all, as the gold standard diagnostic assessing the cause of biliary strictures due to its invasiveness. Secondly, this is a single-center experiment and it will be more precious if carried out as a multicentre study.

\section{CONCLUSION}

EUS-FNA is superior to ERCP with brush cytology in diagnosing biliary strictures, mainly in the assessment of distal lesions due to its superior sensitivity, specificity, and accuracy. Combining ERCP with tissue sampling and EUS-FNA is feasible with highly improved diagnostic accuracy.

\section{ETHICAL APPROVAL}

There is nothing to be declared.

\section{CONFLICT OF INTEREST}

The authors declare no conflict of interest related to this work.

\section{REFERENCES}

1. De Moura DTH, Moura EGH, Bernardo WM, De Moura ETH, Baraca FI, Kondo A, et al. Endoscopic retrograde cholangiopancreatography versus endoscopic ultrasound for tissue diagnosis of malignant biliary stricture: Systematic review and meta-analysis. Endoscopic Ultrasound 2018;7:10-9. doi: 10.4103/2303-9027.193597

2. Moura DTH, de Moura EGH, Matuguma SE, Dos Santos ME, Moura ETH, Baracat FI, et al. EUS-FNA versus
ERCP for tissue diagnosis of suspect malignant biliary strictures: a prospective comparative study. Endosc Int Open 2018;6:E769-E77. doi: 10.1055/s-0043-123186.

3. Yoon WJ, Brugge WR. Endoscopic evaluation of bile duct strictures. Gastrointest Endosc Clin N Am 2013;23:27793. doi: 10.1016/j.giec.2012.12.002.

4. Xu MM, Sethi A. Diagnosing Biliary Malignancy. Gastrointest Endosc Clin N Am 2015;25:677-90. doi: 10.1016/j.giec.2015.06.011

5. Charbel H, Al-Kawas FH. Cholangiocarcinoma: epidemiology, risk factors, pathogenesis, and diagnosis. Curr Gastroenterol Rep 2011;13:182-7. doi: 10.1007/s11894-011-0178-8

6. Schoefl R, Haefner M, Wrba F, Pfeffel F, Stain C, Poetzi R, et al. Forceps biopsy and brush cytology during endoscopic retrograde cholangiopancreatography for the diagnosis of biliary stenoses. Scand J Gastroenterol 1997;32:363-8. doi: 10.3109/00365529709007685.

7. Naitoh I, Nakazawa T, Kato A, Hayashi K, Miyabe K, Shimizu S, et al. Predictive factors for positive diagnosis of malignant biliary strictures by transpapillary brush cytology and forceps biopsy. J Dig Dis 2016;17:44-51. doi: 10.1111/1751-2980.12311.

8. Tummala P, Munigala S, Eloubeidi MA, Agarwal B. Patients with obstructive jaundice and biliary stricture \pm mass lesion on imaging: prevalence of malignancy and potential role of EUS-FNA. J Clin Gastroenterol 2013;47:532-7. doi: 10.1097/MCG.0b013e3182745d9

9. Sadeghi A, Mohamadnejad M, Islami F, Keshtkar A, Biglari M, Malekzadeh R, et al. Diagnostic yield of EUS-guided FNA for malignant biliary stricture: a systematic review and meta-analysis. Gastrointestinal Endosc 2016;83:2908.e1. doi: 10.1016/j.gie.2015.09.024

10. Nagtegaal ID, Odze RD, Klimstra D, Paradis V, Rugge M, Schirmacher P, et al. The 2019 WHO classification of tumours of the digestive system. Histopathology 2020;76:182-8. doi: 10.1111/his.13975.

11. Jo JH, Cho CM, Jun JH, Chung MJ, Kim TH, Seo DW, et al. Same-session endoscopic ultrasound-guided fine needle aspiration and endoscopic retrograde cholangiopancreatog- 
raphy-based tissue sampling in suspected malignant biliary obstruction: A multicenter experience. $J$ Gastroenterol Hepatol 2019;34:799-805.doi: 10.1111/jgh.14528.

12. Dorrell R, Pawa S, Zhou Y, Lalwani N. The Diagnostic Dilemma of Malignant Biliary Strictures. Diagnostics 2020;10:337. doi: 10.3390/diagnostics10050337

13. Novikov A, Kowalski TE, Loren DE. Practical Management of Indeterminate Biliary Strictures. Gastrointest Endosc Clin N Am 2019;29:205-214. doi: 10.1016/j.giec.2018.12.003

14. Korc P, Sherman S. ERCP tissue sampling. Gastrointestinal Endosc 2016;84:557-71. doi: 10.1016/j.gie.2016.04.039.

15. Fusaroli P, Napoleon B, Gincul R, Lefort C, Palazzo L, Palazzo M, et al. The clinical impact of ultrasound contrast agents in EUS: a systematic review according to the levels of evidence. Gastrointest Endosc 2016;84:587-96.e10. doi: 10.1016/j.gie.2016.06.006.

16. Onda S, Ogura T, Kurisu Y, Masuda D, Sano T, Takagi W, et al. EUS-guided FNA for biliary disease as first-line modality to obtain histological evidence. Therap Adv Gastroenterol 2016;9:302-12. doi: 10.1177/1756283X15625584

17. Moura DTH, de Moura EGH, Matuguma SE, Dos Santos ME, Moura ETH, Baracat FI, et al. EUS-FNA versus ERCP for tissue diagnosis of suspect malignant biliary strictures: a prospective comparative study. Endosc Int Open 2018;6:E769-e77. doi: 10.1055/s-0043-123186

18. Nayar MK, Manas DM, Wadehra V, Oppong KE. Role of EUS/EUS-guided FNA in the management of proximal biliary strictures. Hepatogastroenterology 2011;58:18625. doi: 10.5754/hge10531

19. Mohamadnejad M, DeWitt JM, Sherman S, LeBlanc JK, Pitt HA, House MG, et al. Role of EUS for preoperative evaluation of cholangiocarcinoma: a large single-center experience. Gastrointest Endosc 2011;73:71-8. doi: 10.1016/j.gie.2010.08.050

20. DeWitt J, Misra VL, Leblanc JK, McHenry L, Sherman S. EUS-guided FNA of proximal biliary strictures after negative ERCP brush cytology results. Gastrointest Endosc 2006;64:325-33. doi: 10.1016/j.gie.2005.11.064

21. Nanda A, Brown JM, Berger SH, Lewis MM, Barr Fritcher EG, Gores GJ, et al. Triple modality testing by endoscopic retrograde cholangiopancreatography for the diagnosis of cholangiocarcinoma. Therap Adv Gastroenterol 2015;8:56-65. doi: 10.1177/1756283X14564674

22. Wight CO, Zaitoun AM, Boulton-Jones JR, Dunkley C, Beckingham IJ, Ryder SD. Improving diagnostic yield of biliary brushings cytology for pancreatic cancer and cholangiocarcinoma. Cytopathology 2004;15:87-92. doi: 10.1046/j.0956-5507.2003.00097

23. Fritscher-Ravens A, Broering DC, Knoefel WT, Rogiers $\mathrm{X}$, Swain P, Thonke F, et al. EUS-guided fine-needle aspiration of suspected hilar cholangiocarcinoma in potentially operable patients with negative brush cytology. Am J Gastroenterol 2004;99:45-51. doi: 10.1046/j.15720241.2003.04006

24. Rösch T, Hofrichter K, Frimberger E, Meining A, Born
P, Weigert N, et al. ERCP or EUS for tissue diagnosis of biliary strictures? A prospective comparative study. Gastrointest Endosc 2004;60:390-6. doi: 10.1016/s00165107(04)01732-8

25. Weilert F, Bhat YM, Binmoeller KF, Kane S, Jaffee IM, Shaw RE, et al. EUS-FNA is superior to ERCP-based tissue sampling in suspected malignant biliary obstruction: results of a prospective, single-blind, comparative study. Gastrointest Endosc 2014;80:97-104. doi: 10.1016/j. gie.2013.12.031

26. Navaneethan U, Njei B, Lourdusamy V, Konjeti R, Vargo JJ, Parsi MA. Comparative effectiveness of biliary brush cytology and intraductal biopsy for detection of malignant biliary strictures: a systematic review and meta-analysis. Gastrointest Endosc 2015;81:168-76. doi: 10.1016/j. gie.2014.09.017

27. Ohshima Y, Yasuda I, Kawakami H, Kuwatani M, Mukai $\mathrm{T}$, Iwashita $\mathrm{T}$, et al. EUS-FNA for suspected malignant biliary strictures after negative endoscopic transpapillary brush cytology and forceps biopsy. $J$ Gastroenterol 2011;46:921-8. doi: 10.1007/s00535-011-0404.

28. Khashab MA, Fockens P, Al-Haddad MA. Utility of EUS in patients with indeterminate biliary strictures and suspected extrahepatic cholangiocarcinoma (with videos). Gastrointest Endosc 2012;76:1024-33. doi: 10.1016/j. gie.2012.04.451.

29. El Chafic AH, Dewitt J, Leblanc JK, El H, II, Cote G, House $\mathrm{MG}$, et al. Impact of preoperative endoscopic ultrasoundguided fine needle aspiration on postoperative recurrence and survival in cholangiocarcinoma patients. Endoscopy 2013;45:883-9. doi: 10.1055/s-0033-1344760.

30. Draganov PV, Chauhan S, Wagh MS, Gupte AR, Lin T, Hou W, et al. Diagnostic accuracy of conventional and cholangioscopy-guided sampling of indeterminate biliary lesions at the time of ERCP: a prospective, long-term followup study. Gastrointestinal Endosc 2012;75:347-53. doi: 10.1016/j.gie.2011.09.020

31. Nishikawa T, Tsuyuguchi T, Sakai Y, Sugiyama H, Miyazaki M, Yokosuka O. Comparison of the diagnostic accuracy of peroral video-cholangioscopic visual findings and cholangioscopy-guided forceps biopsy findings for indeterminate biliary lesions: a prospective study. Gastrointest Endosc 2013;77:219-26. doi: 10.1016/j. gie.2012.10.011. 